\title{
MOTIVATIONS OF FACULTY ENGAGEMENT IN INTERNATIONALIZATION: AN AGENDA FOR FUTURE RESEARCH
}

Josiah Zachary Nyangau ${ }^{1}$

Louisiana State University, USA

\begin{abstract}
The field of international and comparative education continues to evolve and grow in new and exciting directions. A substantial amount of research exists pertaining to institutional rationales of internationalization. However, little empirical research has focused on why academics engage in activities with international dimensions, especially when this work is not recognized and rewarded in tenure and promotion decisions. This contribution, based on the findings of a larger study, examines motivations of faculty engagement in internationalization and suggests an agenda for future research.

Keywords: Faculty Motivations; Faculty Rewards; Faculty International Activities; Faculty Engagement in Internationalization; Higher Education Internationalization; Higher Education in Africa

\section{Introduction}

Higher education worldwide continues to experience profound changes as a result of developments in the broader economic and political landscape and studies suggest that globalization is a core driver of current trends (Altbach \& Knight, 2007; Altbach, Reisberg, \& Rumbley, 2009; Knight, 2006; Stromquist, 2007). A glance through the literature reveals multiple and compelling definitions of globalization; however, for the purposes of this study it refers to the "economic, political, and societal forces pushing $21^{\text {st }}$ century higher education toward greater international involvement” (Altbach \& Knight, 2007, p. 290). The spread of globalization and the resultant intergration of global economies and expansion of global trade has had multifarious influences on higher education (Altbach, 2016; Altbach \& Knight, 2007), perhaps the foremost of which is the inclusion of education in trade agreements as a tradable "export commodity" (Knight, 1997, p. 9). This liberalization of trade in educational services accelerated a restructuring of systems of higher education in different countries, culminating in today's highly competitive and seemingly borderless marketplace (Altbach, 2016; Altbach \& Knight, 2007).
\end{abstract}

\footnotetext{
${ }^{1}$ Correspondence: Josiah Nyangau, Assistant Director, Office of Institutional Effectiveness, 336 Thomas Boyd Hall, Louisiana State University, Baton Rouge, LA 70803, USA

Email: jnyangau@kent.edu
} 
While systems and institutions of higher education throughout the global landscape struggle to address the pressures created by globalization, internationalization has emerged as a common response to some of the challenges (Altbach, Reisberg, \& Rumbley, 2009; Altbach \& Knight, 2007; Knight, 2004; Stromquist, 2007; Vaira, 2004). The literature lacks consensus regarding the definition of internationalization. Even so, Knight's (2003) conception, which describes it as "the process of integrating an international, intercultural, and global dimension into the purpose, functions, or delivery of post-secondary education" (p. 2) is the most commonly cited. Periodic surveys conducted by the American Council on Education (ACE) indicate that higher education in the United States has witnessed a dramatic proliferation of activities with international dimensions (ACE, 2012; Siaya \& Hayward, 2003). Along the same lines, a growing body of research has focused on identifying institutional rationales for internationalization and Van der Wende (1997) is one of the most influential studies in this regard. The author developed a typology of rationales for internationalization spanning academic, political, socio-cultural, and economic dimensions. In broad strokes, academic rationales focus on the notion of improving academic quality through education exchanges whereas socio-cultural rationales emphasize cross-cultural exchanges to promote greater understanding of other cultures. The political rationales have more to do with expanding a nation's influence through diplomacy (and thus are germane at the national level), and the economic rationales involve revenue-generating motives (de Wit, 1995, 2000; Knight \& de Wit, 1997; Van der Wende, 1997).

The one overarching perspective in the literature is that the field of comparative and international education, particularly international higher education, has continued to grow and evolve in different directions. In this regard, Kehm and Teichler (2007) provide a distilled summary of the broad sweep of developments in the field over the past several decades. Specifically, the authors identify the following themes in the literature: (1) international scholar mobility, (2) mutual influences of higher education systems, (3) internationalization of the substance of teaching and learning (4) institutional strategies for internationalization, (5) knowledge transfer, (6) cooperation and competition, and (7) national and supra-national policies with respect to internationalization (p. 234). Obviously, there are multiple groups of actors, with differing motivations, in the field of international and comparative education, including policy makers, international organizations, academics, practitioners, and parents (Bray, 2016). Although each of these groups of actors contributes substantively to the development of the field, academics occupy a unique space that sets them apart from the others. Specifically, whether conducting systematic analyses of different models of education to produce new knowledge and insights or preparing scholars for the academy or researchers and practitioners for international development organizations, academics play a central role in advancing the field of international and comparative education (Bray, 2016). Interestingly, however, the question of why academics engage in activities with international dimensions, especially when this work is not recognized and rewarded in performance appraisals for tenure and promotion has received little empirical examination. This contribution responds to this problem in the literature by drawing on interviews with faculty who carry the rank of assistant professor or (recently tenured) associate professor and who are involved in internationalization at a large public research university in the Midwestern United States where the prevailing reward structure does not provide recognition and rewards for international activities. Put simply, the study sought to understand the motivations of international engagement for pre-tenure faculty where this effort is not recognized and rewarded as scholarly activity in tenure and promotion decisions. I use the terms "international engagement" in an intentionally broad way to encompass a wide range of 
scholarly and creative activities intended to expose students to international and global perspectives, including curriculum (re)development, design and/or delivery of study abroad programs, and developing and implementing international partnerships.

\section{Context: Tenure and Promotion in the United States}

To advance in their careers, faculty are evaluated based on performance in three primary areas - research productivity, teaching effectiveness, and service to the academy and the profession (O’Meara, Terosky, \& Neumann, 2008). In a balanced model, these areas would be weighted equally, and faculty rewarded for accomplishments in each of the categories. The reality, though, is that tenure and promotion structures, especially at research universities, are restrictive and emphasize research and publications over other scholarly and creative endeavors (O’Meara, 2002; 2005; O’Meara et al., 2008; Rice, Sorcinelli, \& Austin, 2000) including faculty internationalization-related activities (Childress, 2007; 2010; Green, 2002; Hudzik, 2011; Siaya \& Hayward, 2003). Certainly, to truly transform a curriculum or complete a curriculum redesign especially when there is no impetus for it, such as to comply with accreditation requirements, takes a tremendous amount of time and effort. Likewise, to build a new student exchange or study abroad program takes a substantial amount of time, and to lead an education abroad program takes an additional commitment of time. For tenure-seeking faculty, then, a significant and sustained commitment of time to internationalization where the prevailing academic reward structure does not provide recognition and credit for international activities in tenure and promotion decisions carries implicit career risks; it detracts from time for "legitimate" and preferred scholarship (research and publications) and could imperil one's progression toward tenure and promotion. Yet, these perils notwithstanding, there are pre-tenure faculty who, for whatever number of reasons, break out of the "bubble" and commit hours and hours of time and effort to internationalization activities, which then raises two important questions: (1) What draws this group of faculty to individually make this personal and professional commitment to internationalization? and (2) What drives this commitment?

\section{Theoretical Framework}

I used perspectives from three theories commonly used to explain sources of motivation in humans to examine faculty rationales for engagement in internationalization. These include the intrinsic and extrinsic motivation theory (Austin \& Gamson, 1983), motivational systems theory (Ford, 1992), and the self-knowledge and social knowledge framework (Blackburn \& Lawrence, 1995). According to Austin and Gamson (1983), both intrinsic and extrinsic factors are integral to understanding and explaining the construct of motivation among faculty. Extrinsic factors involve the external environment and comprise tangible rewards and incentives, such as tenure and promotion, and faculty work hard to achieve these desired outcomes. Conversely, intrinsic factors refer to those that spring from within an individual; meaning that the rewards are internal and intangible, and faculty engage in activities they find personally meaningful and rewarding, and not because of external awards (Austin \& Gamson, 1983). Nonetheless, critics argue that behavior culminates from multiple and interrelated factors (Blackburn \& Lawrence, 1995; Ford, 1992) and, as a result, Austin and Gamson's (1983) dichotomous framework is limited in its ability to explain sources of motivation.

Motivational systems theory (Ford, 1992) is perhaps the most commonly cited in the literature. Ford argues that motivation is a composite construct that is built on three elements, namely personal goals, personal agency beliefs, and emotions. These elements, 
Ford posits, function in concert "to direct, energize, and regulate" (p. 3) actions intended to achieve desired outcomes. Accordingly, Ford (1992) defines motivation as the "organized patterning of an individual's personal goals, emotions, and personal agency beliefs" (p. 78). Personal goals refer to "desired future states and outcomes" (p. 73); that is, those ends that an individual seeks to achieve. Further, Ford suggests that goals have two basic properties: a content aspect and a process or direction aspect. The content aspect, Ford writes, refers to the "desired or undesired [outcomes] to be achieved (or avoided)" while the process or direction aspect guides efforts and strategies designed to "produce [desired outcomes] or to prevent [adverse outcomes] from occurring" (p. 83). All told, goals address the "why" individuals engage in various activities. In this study, I treated goals as analogous to motivations; both provide the impetus for actions designed to achieve desired outcomes.

Personal agency beliefs comprise two sets of beliefs: Capability beliefs and context beliefs (Ford, 1992). Capability beliefs refer to self-evaluations about whether one possesses the skills or abilities necessary to attain desired outcomes whereas context beliefs refer to subjective evaluations of one's environment in relation to goal-seeking efforts. Here, it is important to bear in mind that perceptions of organizational responsiveness or conduciveness for one's work span two dimensions; the structural dimension (rewards) and the social dimension, which involves judgements about collegial support (Ford, 1992). In short, Ford postulates that individuals with strong capability beliefs and positive context beliefs are likely to persist in pursuit of desired outcomes whereas the converse holds for individuals with weak capability beliefs and negative context beliefs.

The final component of motivational systems theory is emotions, which, Ford (1992) contends, function as a motivating force or antecedents of behavior, thus completing the motivation cycle. Whereas positive emotions focus and reinforce our energy resources directed toward desired outcomes, negative emotions function in the opposite direction; they inhibit activities associated with undesired outcomes (Ford, 1992). That is, they help us avoid certain goals. The strength of motivational systems theory lies in the fact that it is comprehensive and compelling as Ford takes a "systems perspective" and derives from biological, environmental, psychological, and behavioral factors to explain sources of motivation in humans. In short, Ford (1992) attends to the whole "person-in-context" (p. 66). Even so, motivational systems theory is not without its critics. For instance, O’Meara, Sandmann, Saltmarsh, and Giles (2011) point out that Ford's framework focuses almost exclusively on the individual and, as a result, fails to consider other potential drivers of behavior such as socio-cultural, economic, and political factors.

Lastly, I drew upon the self-knowledge and social knowledge framework (Blackburn \& Lawrence, 1995), which explains faculty research and productivity in terms of individual and organizational factors. The authors elucidate that self-knowledge represents ".... selfassessed competence in selected professional activities, as well as one's sense of efficacy in situations" (p.16) whereas social knowledge comprises judgments about collegial support as well as institutional support (rewards) for one's work. Obviously, there is a great deal of overlap between motivational systems theory (Ford, 1992) and the self-knowledge and social knowledge framework (Blackburn \& Lawrence, 1995) as both models integrate Bandura's (1977) construct of self-efficacy; "beliefs in one's capabilities to organize and execute the courses of action required to produce given attainments" (Bandura, 1997, p. 3). Taken together, perspectives from these three theories provide a useful framework for studying motivations of faculty engagement in internationalization. That said, it is important to recall that these theories originated in the West and thus illuminate conceptions about motivation rooted in Western cultures or at least Western contexts. But as scholars in organizational 
behavior remind us, the relationship between motivation and culture (social context) is a complex one (Erez \& Earley, 1993) and, as a corollary, theories that derive from ethnocentric perspectives are "limited in their capacity to explain cross-cultural differences in work motivation” (p. 117).

\section{Literature Review: Faculty Engagement in Internationalization}

Although much has been written about institutional drivers for internationalization (van der Wende, 1997; Knight \& de Wit, 1997), little empirical research has focused on the individual motivations underlying faculty engagement in internationalization, especially when this work is not recognized and rewarded in tenure and promotion evaluations. In an application of de Wit's (2002) framework of rationales for internationalization in higher education, Friesen (2013) used a phenomenological approach to explore factors that motivate faculty involvement in internationalization in the context of Canadian higher education. Friesen's sample consisted of five faculty members drawn from different Canadian research universities. The author found that prior experiences, particularly international mobility and influential individuals and experiences inform faculty participation in activities with international dimensions. Additionally, respondents in that study attributed their involvement in internationalization to the desire to improve the quality of education and to enhance intercultural competence for both students and faculty. Friesen (2013) makes important contributions to the literature; however, there are limitations to her study that are worthy of note. First, the study is grounded in an organizational framework (institutional rationales for internationalization) and, as a corollary, it fails to provide a nuanced perspective on the individual motivations of faculty, particularly when this effort is not recognized and rewarded in performance appraisals. Second, the author does not indicate the tenure status of the study respondents and, perhaps more important, whether policies governing tenure and promotion at respondents' institutions specify criteria for evaluating and rewarding faculty international activities.

Similarly, Beatty (2013) applied Knight's (1994) internationalization cycle to examine rationales of faculty international engagement. Perhaps not surprisingly, the author reports that professional characteristics including tenure status (tenured faculty were more likely to participate), faculty interests, and organizational commitment to internationalization influenced faculty involvement. Further, respondents in that study identified criteria for tenure and promotion as a barrier to international engagement; a finding that is particularly noteworthy since, as Beatty (2013) suggests, guidelines for tenure and promotion provide recognition and rewards for faculty international activities. Moreover, Beatty's findings lend credence to the oft-repeated assertion that policies governing tenure and promotion constrain faculty involvement in internationalization.

Other studies have attempted to develop predictive models, built on data from the Changing Academic Profession Survey (CAP), that relate the odds of faculty engagement in internationalization (Finkelstein \& Sethi, 2014; Finkelstein, Walker, Chen, 2009; 2013). These studies report findings grouped into three categories that constitute important predictors of faculty participation in international activities: Professional characteristics such as rank (senior faculty are more likely participate) and discipline (faculty in the "hard" sciences are more likely to be involved); personal dimensions (e.g., prior international mobility, interests); and organizational characteristics. Although these studies provide important insights into potential drivers underlying faculty engagement in activities with international dimensions, they are not without limitations. First, the CAP Survey captures broad global trends in the academic profession and thus the data available lack nuance and detail and 
second, the authors do not engage the issue of rewards or lack thereof for faculty international activities. The foregoing discussion underscores the fact that explorations of individual rationales of faculty involvement in internationalization are warranted to advance our knowledge in this area. This study drills down in a qualitative way to highlight faculty voices in that regard.

\section{Study Design}

The purpose of this exploratory study was to understand and describe the motivations of international engagement for pre-tenure faculty where the academic reward system of the institution does not incorporate recognition and rewards for internationalization activities in tenure and promotion decisions. The following questions guided this inquiry: (1) What do faculty describe as the predominant motivations for international engagement? (2) What intrinsic rewards do faculty achieve from international engagement? (3) What extrinsic rewards do faculty derive from international engagement?

\section{Sample Construction}

The sample for this study consisted of fifteen $(n=15)$ participants drawn from a college that comprises disciplines in the fields of education, human services, and health professions. The sample was 53\% female and 47\% male, 67\% White, 20\% Asian, 6\% Black, and 6\% Hispanic. Further, eight respondents were from the United States with the rest coming from East Asia, Europe and Africa. Based upon my familiarity with the site and using Patton's (2002) purposeful sampling approach, I recruited the first few subjects and identified additional respondents through a snowball sampling approach. Specifically, I solicited referrals from respondents for colleagues who were also involved in internationalization initiatives. To participate in the study, respondents had to have been involved in activities with international dimensions that were not explicitly recognized and rewarded in the tenure and promotion review process such as (re)developing curricula to integrate intercultural and global perspectives, developing and/or leading education abroad programs, and building international partnerships.

\section{Data Collection}

Data for this study were collected using in-depth semi-structured interviews (Merriam, 2009). My interview protocol included a set of questions I developed and others I adapted and modified as appropriate from Neumann's (2009) study, which explored drivers of faculty "academic passions" post-tenure (p. 17). My study of course differs from Neumann's in fundamental ways; however, at their core both inquiries focus on drivers of faculty actions in relation to their scholarly and creative endeavors. All interviews lasted approximately one hour and a half in length and were audio-recorded and transcribed verbatim.

\section{Analytic Process}

I analyzed the data using the constant comparative method (Glaser \& Strauss, 1967) and consistent with the two-step coding process proposed by Charmaz (2006, 2014). The first step is line-by-line coding and here I read and re-read carefully all transcripts, highlighted text, and created in the margins tentative codes that described the patterns I was noticing in the data (Charmaz, 2014; Denzin \& Lincoln, 2000). The second step in my analytic process was focused coding, which Charmaz (2014) explains, is selective and "more conceptual" and involves "using the most significant and/or frequent earlier codes to sift through and analyze large amounts of data" (p. 138). Accordingly, I reexamined the data and the initial codes, 
compared codes against other codes, and identified a set of "codes [that made] the most analytic sense" (Charmaz, 2014, p. 138). I then selected a set of codes that were consistent throughout the data set and which best captured patterns evident in the data. With tentative categories in place, I sorted and synthesized batches of data and compared categories for further refinement to ensure they were both exhaustive and mutually exclusive (Charmaz, 2014; Merriam, 2009). This process culminated in a set of overarching categories that best describe my findings.

\section{Findings}

Rationales or goals in this study represent the purposes that underlie faculty engagement in internationalization. In this regard, faculty articulated multiple and varied rationales including the desire to facilitate and enhance student learning and development; to prepare global citizens; commitments to issues and causes of personal interest; and to increase reputation of academic programs. These motivations were not mutually exclusive; in fact, respondents often linked their participation in internationalization-related activities to multiple rationales. My analyses also found that enjoyment and personal fulfillment and satisfaction were the most commonly mentioned intrinsic rewards while recognition in the discipline and opportunities to travel and to build international networks emerged as the predominant extrinsic rewards. Lastly, the data showed that prior experiences are important to consider when examining influences that inform faculty decisions relative to internationalization.

\section{Motivation to Facilitate and Enhance Student Learning}

The most frequently mentioned motivation for participation in internationalization related to the desire to facilitate and enhance student learning and development. Faculty involved in cross-border education activities described their efforts in terms of facilitating and promoting intellectual exchanges of knowledge and ideas, which they felt was beneficial to all stakeholders including students and institutions both at home and overseas. To begin with, international experiences enhance faculty global perspectives and benefit their instructional strategies. Mary, for instance, related her belief that cross-border education activities contribute to "improving the educational experience for our students." In this regard, Mary explained that her education abroad program and professional development trainings enrich her teaching practices as she is "able to learn" from others and expand her knowledge about the world, which helps "broaden [her] perspectives" as well as those of her students: "A lot of the countries I go to don't have the education system we have here, but they have brilliant people, very competent people doing amazing things. Why wouldn't we want their ideas?"

Joy echoed these sentiments and noted her belief that international engagement initiatives provide faculty with opportunities to "learn from other systems of education [and to ] bring back new innovations" and, in so doing, enrich student learning. Similarly, Allen, who is involved in professional development trainings for faculty at vocational education and training institutions, shared his broad goals to promote exchanges of knowledge and ideas and to enhance the pedagogical practices of educators at participating institutions. In this regard, Allen hopes that the faculty he works with add to their courses the global perspectives they gain and adapt and implement the new instructional strategies they learn in their classrooms. Rachel was more succinct and direct in relating her motivation to "bring back [to her home country] best practices" in her discipline, and to spark and "facilitate discussions 
on how to improve the [education] system," thus contributing to "the greater good." She explained,

We have a strong special education system in [home country], but still a lot of good things can be done and the U.S. has the most advanced knowledge and best practices so partially I am learning from [the system] here in the U.S. and then figuring out how to adapt it in a way that can help my own country.

Simply put, Rachel derives "a sense of achievement” from knowing that her work promotes new approaches to teaching and learning and "contribute [s] to the growth and development of the education system" in her home country.

Furthermore, respondents were persuaded that study abroad, and the cognitive dissonance which the experience often creates, benefits students in terms of increasing academic achievement and enhancing personal growth and development. As John aptly noted, students who study abroad accrue "profound educational and personal and professional benefits," which they find useful beyond their college careers. One of the reasons why respondents felt that study abroad is important is that it provides students with "stimulating" and "exciting" learning opportunities in real-world settings and, as a result, it has the potential to facilitate increased understanding of course content and overall academic achievement. For instance, Mary postulated that a study abroad component of a course offers students opportunities to reflect on their learning in the classroom and to apply their knowledge in a real-life context. As a result, the experience increases student engagement in a course and enriches learning, thus facilitating greater understanding of course content and ultimately improved academic achievement. Similarly, John underscored the potential of study abroad to support and foster deeper learning; it is an "extremely positive [learning] experience that surpasses the kinds of positive experiences [students] have in a traditional classroom," he averred. Drawing on his experience, John further observed that "the learning that happens" during study abroad "seems to be a little more dramatic" as he has noticed a "remarkable" difference in his students after the experience; "They are different in [subsequent] classes, they are a little more confident in themselves [and] they are a little more outspoken in discussions." With the following anecdote, John postulated about the potential of study abroad to motivate and "turn-around" struggling and/or at-risk students:

The real change was this one [student] who was just not doing well in school, he was really struggling -- something clicked during the study abroad and he came back and we talked and he was like "no, I am going to focus on school, I see this is really important." He became an A/B student after that, wound up graduating, and got a job. Prior to the study abroad, he was a D - student looking at a seven-year program. I think the study abroad gave him a new perspective, it just motivated him to be a better student afterwards.

All in all, John believes that international experiences help students "recognize that they are capable of a high level of understanding and [academic] performance" if they are dedicated and engaged.

Another reason why respondents thought that study abroad was important relates to the personal and/or professional growth and cognitive development that students who participate potentially achieve. The experience, according to John, offers students valuable 
opportunities for active participation in leadership and self-reflection, leading to increased awareness of self and others. In this respect, it has the potential to transform both student learning and student attitudes:

Confidence is a big one where at least with [my] trip, because it is really challenging for a student who has never left [home] and now you are taking them half way around the world, and they are in completely different settings. By the end of the trip students look back, they reflect and they say, "I overcame that challenge, I did something I never would have imagined myself doing." The experience boosts their self-confidence in their own abilities to take on new challenges and to perform complex tasks ...

This increased sense of self-confidence, John concluded, benefits students in different areas, "It benefits them at school, at job applications, career opportunities, and with interactions with other people." Joy shared these views and described study abroad as a "life-changing experience" that provides students with opportunities to explore, to learn about, and to appreciate different cultures and differences in ways of knowing; it helps students understand that "there are different solutions to different challenges and other people are trained to do things differently and that is not necessarily wrong, [it's] just different," she elucidated.

Overall, activities with international dimensions portend valuable outcomes for all stakeholders. The importance of these experiences to enhancing student learning and growth in a variety of ways and in different contexts emerged as a major theme pervading the data; these experiences challenge students to "open their minds and contemplate new ways of thinking about the world" (Allen) and in so doing "develop new, global perspectives" (John). Similarly, faculty involved in internationalization activities gain valuable knowledge and perspectives, which they integrate into their courses thereby benefiting students.

\section{Motivation to Prepare Global Citizens}

Another rationale that respondents commonly articulated relates to the desire to prepare global citizens. My analysis revealed that respondents perceived the notions of "global citizenship" and "global marketplace" as inextricably linked. More specifically, their framing of the motivation to prepare global citizens was broad and oriented around the notion of equipping students with the requisite knowledge, skills, and dispositions for "global citizenship" and for success in the contemporary "global marketplace." For instance, John spoke about his goal to "expose students to different cultures and different perspectives" and to prepare them for an increasingly multicultural workforce: "Students [need] to understand that different systems work differently, and different people have different values and they have to learn to work with culturally different others," he stated. Dan echoed these assertions noting that "citizenship is a very important aspect of training" in an increasingly global business environment. "We need to educate people who are going to be working somewhere out there in the world," Dan stated, adding:

You cannot talk about nationalism in the business environment [anymore]. For example, if you buy a Hyundai today, what kind of car is this? Is it a Korean car? No, it is not -- It is made in Alabama. [But] it is a Korean car, right? But it's made by American workers in Alabama, and they're very proud of it. So what kind of car is that exactly? 
Dan deems citizenship training as essential for graduates to develop the skills and knowledge necessary to interact and work "successfully with Korean managers [who may] come to Alabama." Several other respondents expressed similar perspectives seeing global citizenship as essential for students to compete and thrive in an increasingly global workplace. Luke spoke about his motivation to ensure learning experiences prepare students adequately to work with "the diversity of people they are likely to come into contact with in their careers" whereas Lily articulated a desire "to prepare students to live in a global society [and] to know [how] to work with people from all over the world [and] to make sense out of what happens beyond our own borders." In this regard, Lily is committed to exposing students to "multiple perspectives [because] they are not going to work in a place where they are going to be around people who are just like them all the time..."

For Allen, the increasing global interconnectedness provides the impetus for and exemplifies the need to prepare students to become leaders and engaged citizens in a complex world. To illustrate his point, Allen cited recent events around the world including the Ebola epidemic that occurred in 2014 (and the global response to it) and the Tsunami that devastated Japan in 2011 and situated them in the broader global context in terms of their impacts on livelihoods beyond national borders. "Think about the Tsunami that happened in Japan - you know, okay it doesn't affect us, it is miles away from here, but think about what kind of an impact -- how did that affect us in everyday life..." particularly with respect to the shortage of Japanese cars and related effects on businesses and families here in the United States. Allen thus believes that international experiences help students achieve a greater and nuanced "understanding of [complex] global issues." Simultaneously, Allen invoked "employer push" as part of his rationale for internationalization activities saying, "Surveys of employers of graduates [from our program] consistently indicate that the vast majority overwhelmingly" desire to hire graduates with both the "technical expertise and the soft skills including strong communication skills and cross-cultural awareness." All told, respondents shared a broad range of perspectives related to the constructs of preparing globally competent citizens as well as preparing students for success in a global marketplace. Taken together, these perspectives underscore an oft-repeated assertion that graduates today are likely to be employed in international and/or multicultural settings; therefore, the ability to work effectively across cultures becomes essential to success.

\section{Motivation Rooted in Political and Social Issues}

Several respondents attributed their involvement in internationalization initiatives to their enduring commitments to political and social issues and causes of interest. Two subgroups, each consisting of four participants, emerged under this category. In the first subgroup, respondents discussed their motivations in terms of promoting social justice and inclusive education. The commonality among the four participants is that each struggled with marginalization in the past, and all felt that their prior experiences shape and inform their scholarly and creative activities. Luke framed his motivation as "always about social justice," and explained that his experience "makes [him] more aware" of diverse voices and perspectives and sparked in him "a passionate commitment" to facilitate the voices of those who often go unrecognized and/or unrepresented. In a similar manner, Valerie shared that marginalization ignited in her "a feeling of advocacy and a passionate commitment to the cause of social justice." Accordingly, Valerie's initiatives to integrate intercultural and international perspectives into the curriculum are grounded in a desire to make certain that the diversity of "voices and experiences that often go unheard or unrepresented at the table" are included. Reflecting on the scholarship in her discipline, Valerie noted that counseling 
theories generally derive from Western ways of knowing, which has its own limitations in an increasingly multicultural society: "We need to understand that our ways of doing things in the counselling profession are not going to work in other countries and other cultures," she observed and discussed the need for the literature in her field to be more responsive to and inclusive of other perspectives instead of "trying to impose our own values." Correspondingly, Austin talked about using his "position of privilege [to] convey the concerns" of those whose voices are marginalized, as the education system in the United States "needs a good deal of help." Thus, for some internationalization serves as a tool or offers a pathway for purposefully infusing intercultural and global content into courses to ensure educational experiences reflect and value multiple and diverse perspectives.

In the second subgroup, respondents linked their international engagement initiatives to a desire to promote collaboration and mutual understanding in a global society. These respondents, all with social ties to the Northeast Asia region, perceived international engagement as a vehicle for bringing together different groups of people from different cultures, thus fostering collaboration and relationship building and ultimately contributing to peaceful coexistence. Ben, for instance, thought that the flagging "political relations" between the United States and countries around the Northeast Asia region, as well as the tensions among countries in that region, are the result of what he described as a "lack of understanding between the different cultures." In this regard, Ben related his overarching goals to "bring together groups of students from different cultures [through] a peer mentorship program [where] international students and local students study together and learn from each other." Ben views the ensuing exchanges as critical to helping students learn more about others, and thus become "confident to operate in other cultures," and to nurturing meaningful and "culturally responsive relationships." Taking the long-term perspective, Ben described his work as an investment in "future leaders" and believes that it lays a foundation for constructive engagement and "building bridges between different countries." "I believe that in the future it will happen -- one day," he concluded.

Rachel similarly discussed her motivation "to bridge communications between different countries" in the Northeast Asia region and the U.S., and ultimately "to influence policy change" in a way that contributes toward sustained "peace and security" in that region. Mutually beneficial "cross-university collaborations," Rachel explained, establish a framework for mutual understanding and cultivate valuable contacts and relations, which help strengthen cooperation and knowledge and/or policy learning and sharing:

Through student or faculty exchange programs, the universities who have a memorandum of agreement in place will be able to share how they prepare future professionals, the system and resources in place to support the student or faculty exchange programs, and other related aspects for building and sustaining such programs. Once the students graduate from the university and choose to work for state or federal government, or when faculty members serve on advisory boards at the state or federal level, they may be able to make relevant recommendations at the policy level based on what they observe and learn from another country.

To Rachel, although the education and training exchanges and partnerships initially focus on specific initiatives, the culminating goodwill could spark additional and broader collaboration on other areas of mutual interest. Overall, these comments illustrate the role of higher 
education in advancing cross-cultural and intercultural understanding and more broadly, its potential to impact policy directions in society.

\section{Motivation to Increase Reputation of Academic Program}

Perhaps unsurprisingly, some respondents were involved in internationalization for instrumental purposes. Specifically, three respondents perceived international engagement as a vessel for increasing the visibility, recognition and reputation of their programs; it "puts [the university] on the map in terms of what separates our program from others" in the state and around the country, Joy Averred. Likewise, Lily was inspired to improve and to promote her program and "set it apart" in the marketplace:

The recognition of our program influences my commitment quite a bit -- for me, it is all about strengthening our program and strengthening our contribution here in [the state] as well as all over the country. I am at a place in my career where I am very invested in our program being recognized. It is important to me that we have that recognition, that visibility because it helps us stand out in an area that is so diverse and that helps us to highlight our contributions in that diverse environment.

Lily's comments underscore the competitive environment in higher education today and perhaps more important, how programs (and institutions) adapt and position themselves for sustained growth. As Lily further noted, internationalization "is a strong selling point" for her program's recruitment efforts:

When I tell prospective students in front of their parents that we are internationalizing the curriculum, all of the parents vigorously nod their heads like "Yes! You are on the right track." There is lots of affirmation, and that suggests that there are parents out there who think that this is valuable and important.

These excerpts demonstrate some of the practical benefits internationalization brings to academic programs, especially as it relates to long-term viability and success.

\section{Intrinsic Rewards and Extrinsic Rewards}

The overwhelming majority of the respondents commonly identified enjoyment, personal fulfillment and satisfaction as the predominant intrinsic rewards achieved from international engagement. Specifically, they described their work variously as "fulfilling," "gratifying," "exciting," "what I like to do," "fun," "makes me feel good," "makes me feel great inside," and "it is the right thing to do." John, for instance, felt intrinsically rewarded seeing his students learn in study abroad settings:

When I see students having these experiences, it just makes me feel great inside. I enjoy it, I feel good about it, it is satisfying, and it reinforces my beliefs about what motivated me to be involved -- it makes teaching and learning more enjoyable, exciting, and fun, so that is something that just excites me.

Valerie, too, found "joy [and] excitement" in international engagement; "There is always that altruism that you feel good in what you are doing. I enjoy what I do," she observed. Lily 
concurred and described her work as "personally meaningful [and] fulfilling" despite the lack of rewards; "I don't really care if it is in the handbook or not," she stated. Rachel derives a "sense of fulfillment or achievement" from her professional development initiatives overseas:

Every time you see positive feedback from those teachers in China about they do learn something, they feel like their training is very helpful ... it really makes you feel good that you are doing some really good things.

All told, respondents found fulfillment and satisfaction in the richness and reciprocal benefits that international education initiatives provide to all stakeholders.

By contrast, all respondents struggled to articulate extrinsic rewards they derived from activities with international dimensions. Nonetheless, some found recognition in the discipline extrinsically rewarding; specifically, the opportunities that international engagement provides could benefit one's career in terms of expanded professional networks and related concomitants including influence and/or impact in one's discipline. In this respect, Rachel spoke about the possibility of being recognized in one's field as "an opinion leader" on matters related to internationalization. Likewise, Austin viewed "cultural capital, the idea that you have capital in things other than money," as an asset that derives from international engagement. "It gets me a little bit more status in some ways -- every once in a while, it gives me the ability to negotiate things like travel budgets differently," he postulated. In brief, these respondents perceive as an extrinsic reward the "status" that may be achieved or reinforced by international engagement and expertise. Another extrinsic reward that respondents described was opportunities for international travel. Austin found rewarding travel abroad to "see education as it exists in other places" and to "establish personal and professional relations [that are] very valuable." Joy echoed this point when she spoke about the ineffable benefits of international engagement to one's life and career; "I just tend to enjoy people, I made just really good friends internationally and it just brings such richness into the conversation beyond what you would normally maybe experience," she elucidated.

The common theme among participants' responses was the lack of recognition and rewards for faculty internationalization-related activities. "Looking at the handbook," Luke shared, "there appear to be no rewards particularly for the aspects of internationalizing the curriculum -- I can't really think of any." Luke thus seemed resigned to the fact that his efforts relative to internationalization "would not be considered in [his] reappointment reviews." Isabell affirmed this viewpoint saying,

I don't see it being rewarded at all -- it just gets lumped into 'service' with everything else. When I go up for reappointment or tenure, I don't see where the fact that I am doing international work, I don't see where it would benefit me over doing something locally.

These comments are illuminating especially when juxtaposed with Ben's assertion that "faculty can easily fulfill the [service] requirement by serving on a couple of committees on campus." To be sure, international engagement as a "high-impact" initiative may provide opportunities for engaged faculty to "stand out" a little bit more for creativity in instructional approaches in the tenure review process. However, as John aptly pointed out, "Faculty could still demonstrate innovative instructional methods without a significant and sustained commitment to internationalization.” 
In light of the lack of recognition and credit, intrinsic rewards emerged as a stronger driver of faculty engagement in internationalization. "Rewards are non-existent, or they are very little and yet I keep doing it, which clearly indicates more of a desire from within than it is from outside," Allen stated. "You do it really for intrinsic reasons, there's not a lot of extrinsic reasons" other than "the student experience," John stated, adding:

I mean [study abroad] is more work than a regular class for the same price, so you are not really doing it for the money. I can get paid the same amount for teaching a three-credit course on campus that would be much less work, right?

If there are two overarching takeaways from this discussion, the first is that the products of international engagement, such as enhanced student learning and the mutual intellectual exchanges of knowledge and ideas among faculty and other stakeholders, are intangible as opposed to concrete outputs (publications) that may be presented in tenure and promotion dossiers. The second is that the lack of a framework for addressing faculty scholarly and creative activities relating to internationalization implies that faculty efforts in this area receive little to no credit in performance appraisals. Ben aptly summed up the nature of the issue with this excerpt: "The problem with international is we don't know how to assess things. That is really the bottom line."

\section{Prior Experiences}

Prior experiences and events surfaced as an important, albeit secondary, aspect to consider in relation to faculty international engagement. In discussing how they became interested and ultimately involved in activities with international dimensions, respondents often invoked prior experiences, which they felt piqued their curiosity and informed some of their eventual career decisions. The experiences and events respondents shared span a broad spectrum, ranging from influential individuals to family background to international mobility. The first and perhaps foremost relates to faculty champions of internationalization and the influence they exercise on colleagues to participate. The faculty champion is not necessarily a formal leader; rather, the champion is a senior colleague with pertinent experience and is a leader in the field whom faculty look up to for guidance and leadership as regards internationalization. Thus, the champion's most important role involves consulting with faculty and providing resources to scaffold efforts to address intercultural and global perspectives in the curriculum. Lily, who did not have much experience or expertise with internationalization, described the faculty champion as "somebody who is just great at getting people excited," someone who helps "rally the troops." She explicated:

If someone came to me tomorrow and said, "Internationalize your courses," I first of all totally wouldn't even have known what that meant until recently and I would not have had any idea how to do that on my own.

However, the faculty champion's leadership and "concrete strategies" made the process "feel very deliberate, very structured, and very manageable" for Lily and, as a result, "it [was] a lot easier to internationalize the curriculum than beginning from scratch." Luke expressed similar views when he recalled how he became involved in a curriculum review initiative to infuse global perspectives: "I was excited when I started to hear a couple of years ago about [the champion] and her initiative to internationalize the curriculum in our 
program and I have been involved with that effort" as well. Similarly, Rachel noted that the champion provides colleagues a "jumping off point." While the faculty may "have the skills, the initiatives, the passion, and the interest," Rachel postulated, the champion serves an important purpose in providing "the steps to get us there and that makes it much more likely that we are going to be successful." These comments provide evidence regarding the critical role that faculty champions play in the success of curriculum internationalization initiatives; they support and facilitate and coordinate faculty efforts, thereby making the experience "as seamless as possible" (Lily).

Additionally, the data showed that family background and international mobility contribute to and/or shape faculty decisions of engagement in internationalization. John, for instance, thought that his family background established a foundation for his desire to explore the world: "Listening to my parents who grew up [overseas], just hearing stories about life in the old countries raised my awareness of the bigger world and perhaps prepared me to want to get out there and explore it." John went on to volunteer with the Peace Corps, an experience he variously described as "informative," "influential," and "transformative." As a professor, John developed and leads a study abroad program where he is inspired to provide "opportunities for students to have those [transformative] experiences ...to go out there and make a difference" in the world. He elucidated,

I recognized in my own experience how important it is for a broader education and that's why as soon as I started looking for teaching jobs, I was already in the interview process talking about internationalization, "I am going to start a study abroad, one of the things you are going to get with me is someone who is going to bring this into the classroom, I am going to be making it relevant to students ..."

Mary, too, perceived links between her prior experiences, where she immersed herself "in different cultures" and learned from "different systems," and her current international engagement initiatives. Further, Mary believes that her family tradition of being active in the church, especially in international outreach and mission work, sparked her initial curiosity about the world and got her "thinking about different cultures and lands and people and their perspectives and why they have those perspectives," experiences which she credits for shaping some of her career decisions. In the same manner, Alice shared how her experiences at her private practice as a speech language pathologist affected her decision to incorporate intercultural and global dimensions into her courses after she became a faculty member: "Well, one [experience] was just my clinical work of seeing what was coming in the door and thinking about that." Alice was referencing the changing demographics in her city and the country in general and noted her lack of pertinent cross-cultural knowledge and perspectives from a career preparation standpoint:

As a clinician, I worked with individuals from lots of different cultures -- I had Orthodox Jewish clients, I had Russian immigrant families, I had Muslim families, and I realized that there were some things I needed to be attending to in order to be effective with these clients that wasn't part of my education.

With the following anecdote, Alice illustrated a larger point regarding the need to prepare practitioners to work effectively with diverse populations: 
I worked with a little boy who had autism from the United Arab Emirates ... and although he came with his dad and his mum, his dad brought him to the sessions and we had to figure out ways to communicate what we were talking about to the mom, we had to have an interpreter, and before he would leave the session he had to dress up in his formal attire and I just started thinking, "wow, we are not prepared for this" and I realized "gee, as a clinician if I don't have this global perspective I am not going to be effective with my clients."

In general, respondents shared a diversity of prior experiences and events, which they felt shaped both their lives and their careers in important and meaningful ways.

Altogether, the data showed that faculty become involved in internationalization for a variety of rationales. More important, the findings of this study reveal practical implications for higher education leaders seeking to foster faculty engagement in international and global activities and initiatives.

\section{Discussion and Policy Implications}

This study produced valuable empirical evidence that extends our knowledge and understanding of motivations that underlie faculty international engagement. When examining rationales of faculty international activities, one reasonably expects the strongest drivers to comprise opportunities and experiences that accrue benefits to participants. Yet a closer scrutiny of the motivations that respondents in this study described shows that they all seem altruistic in nature, which suggests new and interesting perspectives.

Analysis showed that the majority of the participants discussed their motivations for internationalization in terms of facilitating and enhancing learning experiences for students. Specifically, faculty involved in cross-border education activities benefit from the mutual exchanges of knowledge and ideas, which they integrate into their own pedagogies, thus enriching the learning experience for students. Additionally, respondents felt that international experiences benefit students in terms of academic achievement and personal growth and development. As it relates to educational benefits, programs that provide rich learning opportunities facilitate increased understanding of course content, which in turn contributes to enhancing overall academic achievement and success for students. In the same manner, study abroad exposes students to dissonant experiences, which foster personal growth and cognitive development. This notion that international experiences enhance students' psychosocial and cognitive skills echoes prior evidence suggesting positive associations between student engagement in active and educationally meaningful learning activities and success and development (Carini, Kuh, \& Klein, 2006; Clarke, Flaherty, Wright, \& McMillen, 2009; Kuh, Kinzie, Buckley, Bridges, \& Hayek, 2006; National Survey of Student Engagement, 2007). Furthermore, at the broadest level of analysis my findings corroborate existing research indicating that faculty embrace activities related to the scholarship of engagement (Boyer, 1990, 1996) including internationalization (Beatty, 2013; Friesen, 2013; Niehaus \& Williams, 2016) and service learning (Abes et al., 2002; Darby \& Newman, 2014; Hammond, 1994; O’Meara, 2008) to improve educational outcomes for students.

The data revealed that several respondents were motivated to prepare global citizens. Further, respondents' framing of this motivation was broad and encompassed equipping students with skills and competencies for global citizenship and for success in an increasingly competitive global marketplace. Analysis determined that faculty perceived the notions of global citizenship and success in the global marketplace as inextricably linked; that is, through internationalization-related activities and initiatives, students achieve the outcomes 
necessary for both citizenship and success in a global workplace. Although respondents were unambiguous about the motivation to prepare students for global citizenship, it became clear from analysis that their conceptions of citizenship leaned strongly toward the dimension of global competence, one of the elements of global citizenship. This was evident as they spoke consistently about their commitments to foster increased self-awareness, global awareness, and intercultural and cross-cultural competence among students.

The finding that faculty are motivated to prepare students for citizenship and for workplace and career success underscores the complex environment in which higher education today operates. With dwindling resources and rising costs, stakeholders including government, employers, parents, and students increasingly focus on the "value" of a college education; a debate which inevitably centers on "demonstrable outcomes" such as evidence of student achievement or success after college (Jones, 2014; Knight, 2008; Knight \& Yorke, 2004). Additionally, in view of the increasing global economic integration (Altbach \& Knight, 2007), multinational corporations are emerging as some of the leading employers of graduates (Knight, 1999). In light of these prevailing circumstances, it is conceivable that faculty are motivated to prepare globally competent citizens equipped with the tools necessary for success in a dynamic, knowledge-based economy. Still, although higher education is generally construed to serve multiple purposes in a postmodern society, this finding raises the question whether the focus has shifted dramatically in the direction of career preparation and success.

Nonetheless, it is important to bear in mind that the definition and interpretation of the concept of "global citizenship" in the literature is contested. For example, Morais and Ogden (2011) define global citizenship as a composite construct that incorporates "the interrelated dimensions of social responsibility, global competence, and global civic engagement" (p. 449). The authors explain that social responsibility comprises an understanding of the interconnected and interdependent nature of the world as well as "social concern to others, to society and to the environment" (p. 447). Correspondingly, global competence revolves around self-awareness and awareness of others whereas global civic engagement involves active, informed public participation to address societal challenges (Morais \& Ogden, 2011). Other studies conceptualize this multifaceted construct somewhat differently. Eyler and Giles (1999) propose a five-dimension model for assessing citizenship outcomes for students in service learning programs. The five dimensions include values ("I ought to do"), knowledge ("I know what I ought to do and why"), skills ("I know how to"), efficacy ("I can do, and it makes a difference"), and commitment ("I must and will do;" p. 157). The lack of a clear conception of "global citizenship" notwithstanding, three elements, namely social responsibility, global competence, and civic engagement are commonly described as constituting citizenship (Morais \& Ogden, 2011 ; Schattle, 2009).

The data also revealed that commitments to political and social issues and causes of interest motivate faculty engagement in internationalization. As noted previously, there were two subgroups under this category. We saw that respondents in the first subgroup grounded their involvement in internationalization in a commitment to social justice and social change in education. This brings into focus the oft-repeated assertion that Western epistemology dominates the process of knowledge production and often tends to (re)produce local epistemologies as irrelevant or even nonexistent (Gordon, Miller, \& Rollock, 1990). Given this dominance of Western epistemology in educational spaces and experiences, these respondents' view of internationalization as a vehicle for infusing multiple and diverse perspectives into course content to ensure a more inclusive educational experience for students becomes especially evident. 
We also saw that respondents in the second subgroup related their motivations as a matter of promoting opportunities for international collaboration and partnerships. Specifically, these respondents felt that cross-border education activities bring together individuals from different cultures and foster constructive engagement and mutual understanding. Ben aptly summed up this perspective when he described his initiative to establish a "peer mentorship program" with a goal of bringing together and engaging "future leaders" from different cultures. In addition, Ben shared his belief that these efforts culminate in "meaningful and culturally responsive relationships." This assertion is indeed congruent with scholarship suggesting that integrating with host cultures increases cross-cultural knowledge and awareness and decreases stereotyping rooted in cultural perspectives and perceptions (Carlson \& Widaman, 1988; Knight, 2008).

Further, on a structural level some were convinced that university linkages and partnerships cultivate relations and foster goodwill, which could potentially spark additional cooperation in other areas of mutual interest. The foregoing discussion leads one to extrapolate that international education activities provide a structured environment in which international faculty "give back" to their home countries in support of issues and causes of interest. Moreover, the impression that international faculty are motivated to promote opportunities for collaboration brings into sharp focus the concept of "brain circulation," which implies that cross-border mobility of skilled labor benefits countries on both ends of the continuum (Ackers, 2005; Knight, 2008; Spaulding \& Flack, 1976). On the whole, the finding that commitments to political and social issues and causes of interest motivate faculty involvement in internationalization-related activities and initiatives resonates with previous studies examining drivers of faculty scholarship (Abes et al., 2002; O’Meara, 2008; Pollack, 1999). Specifically, O’Meara (2008) found that "personal commitments to specific social issues, people, and places" (p. 14) underlie faculty community engagement.

The last motivation respondents articulated relates to the desire to strengthen academic programs. Some respondents viewed internationalization as instrumental to increasing the visibility, "brand" awareness, and prestige of their programs, the culmination of which includes, inter alia, higher enrollments particularly for international students, increased revenues, and ultimately long-term viability in an otherwise crowded and competitive higher education marketplace. Additionally, the data showed that deliberate and coordinated efforts existed within the human development and family studies program to add learning outcomes relating to international and global perspectives in response to needs in the marketplace. Broadly conceptualized, this finding comports with prior research indicating that economic rationales drive institutional decisions for internationalization (de Wit, 1995; Knight \& de Wit, 1997; Knight, 2008; Stromquist, 2007).

As previously noted, criteria for tenure and promotion at the institution of study do not incorporate recognition and rewards for faculty activities with international dimensions. Accordingly, much as in prior research intrinsic rewards including enjoyment, personal fulfilment and satisfaction emerged as stronger motivators for international engagement (Beatty, 2013; Niehaus \& Williams, 2016). In this category I would also add professional learning; as the data revealed, international and intercultural experiences benefit participants' careers in intangible ways. Furthermore, as with previous research this study found that the lack of recognition and rewards and heavy time demands cause recalcitrance on the part of faculty toward activities with international dimensions (ACE, 2012; Beatty, 2013; Childress, 2010; Dewey \& Duff, 2009; Niehaus \& Williams, 2016; Nyangau, 2018; Siaya \& Hayward, 2003). The data demonstrated that in light of the lack of incentives, faculty conceptualize and describe extrinsic rewards in the abstract. Moreover, respondents expressed strong feelings 
noting that the absence of recognition and rewards constrains meaningful involvement in internationalization initiatives. Under these circumstances and given the realities of the tenure and promotion review process, probationary faculty are compelled to make a value judgment regarding involvement in internationalization activities. Still, one reasonably speculates whether there are unstated extrinsic benefits that accrue to faculty as a result of international engagement. Here, student evaluations of course and teaching effectiveness come into focus and one supposes that to the extent students find internationalization activities rich and meaningful, they are likely to provide positive course evaluations, a potential benefit for instructors.

With the faculty reward system providing no incentives, only "true believers" of internationalization are likely to participate in the various aspects of it. Yet even for the most enthusiastic adherents and advocates, there is likely a tipping point at which the costs vastly outweigh the benefits of a sustained commitment to internationalization. That is, the point where it is no more about the lack of extrinsic rewards, but also that involvement portends a negative impact, especially on probationary faculty progress toward earning tenure. Joy aptly captured this perspective when she remarked that the risks are real, including "the threat [of] losing your job." Furthermore, the lack of a framework for evaluating and providing recognition and rewards for the body of work faculty produce relative to internationalization suggests direct implications for recruitment and retention. Specifically, with little effort institutions that have codified international and global engagement within their tenure and promotion guidelines are likely to lure away faculty who value this work. Taken together, these findings illuminate the need to review and reform policies and practices governing tenure and promotion to incorporate recognition and rewards for faculty internationalization activities.

Finally, my findings echo existing research showing that prior experiences and events shape and inform faculty decisions of involvement in internationalization (Childress, 2010; Ellingboe, 1998; Finkelstein \& Sethi, 2014; Finkelstein et al., 2013; Friesen, 2013; Green, 2003; Green \& Olson, 2003). Perhaps more than any other, analysis revealed that faculty champions of internationalization are essential to fostering broad-based participation among colleagues. Specifically, champions provide valuable scaffolding and leadership, which helps faculty navigate real or perceived barriers to internationalizing the curriculum. This finding evokes Heifetz's (1994) construct of informal leaders and informal authority where he posits that informal leaders are individuals within organizations who exercise influence not because they hold formal positions of authority, but because of their ability to mobilize and rally colleagues to a cause. Heifetz further suggests that informal leaders derive their influence from strong relationships with colleagues throughout an organization. Thus, for higher education leaders seeking to foster and/or scale up faculty involvement in activities with international dimensions, this finding underscores the need to seek out and develop a broad network of champions or advocates to support faculty efforts. More broadly, the notion that prior experiences inform and influence faculty engagement in internationalization raises the question whether institutions can successfully internationalize their programs by merely hiring faculty with relevant prior experiences. Based on the findings of this study, without reforms to add criteria for evaluating and rewarding faculty internationalization activities to policies governing tenure and promotion, this approach would achieve limited success.

\section{Perspectives on Faculty Engagement in Internationalization in Africa}

The continent of Africa is vast, with many countries and diverse systems of higher education several of which are shaped and influenced by different colonial legacies (Weeks, 
2008; Teferra \& Altbach, 2004). As a result, continent-wide perspectives on patterns of faculty engagement in internationalization risk rendering oversimplifications and generalizations of the complex and nuanced realities present in each of the countries (Weeks, 2008; Teferra \& Altbach, 2004). Nonetheless, I draw on the overarching themes already established in the literature and cast a broad lens to discern drivers of faculty international activities. My goal here is to extend the foregoing discussion and to postulate about the individual drivers of faculty engagement in internationalization in the context of higher education in Africa.

We know that institutions of higher education pursue internationalization for a variety of reasons (de Wit, 1995; Knight, 2008; Knight \& de Wit, 1997; Kot, 2016) and contextual factors along with institutional priorities play an important role in determining institutional pathways in that regard (Knight, 2008). Moreover, one would reasonably anticipate variability in rationales for internationalization between geographic regions, between countries in the same geographic region, or even between institutions within the same country. The periodic Global Survey on Internationalization conducted by the International Association of Universities (IAU), a member-based organization, provides important contextual information. The $4^{\text {th }}$ Global Survey conducted in 2013 featured 1,336 institutions of higher education from 131 different countries, with each world region represented. The distribution of response rates varies from country to country and region to region; 604 institutions (45\%) from Europe participated in the survey whereas 253 (19\%) from North America, 164 (12\%) from Asia and Pacific, 141 (11\%) from Latin America \& the Caribbean, and only 114 (9\%) from Africa responded (Egron-Polak \& Hudson, 2014). The low participation rates from institutions located in the global South notwithstanding, the survey provides a more holistic view of the complex and interrelated global and regional trends in internationalization.

Broadly speaking, the findings of these surveys on internationalization have remained fairly consistent across time, indicating that the top three drivers of internationalization for institutions of higher education globally are to prepare students for the global society, to improve the quality of teaching and learning, and to strengthen research (Egron-Polak, 2012; Egron-Polak \& Hudson, 2014). However, interesting differences emerge when the data are disaggregated with respect to the key purposes underlying internationalization initiatives for institutions in the different world regions. Specifically, the surveys show that the top-ranked drivers for international activities for institutions in North America and Western Europe are to prepare students for a global society and to internationalize the curriculum. By contrast, the top-ranked rationales for internationalization for institutions in Africa are to strengthen research collaborations and knowledge production (Egron-Polak, 2012; Egron-Polak \& Hudson, 2014; Knight, 2008).

To be sure, internationalization is a broad and composite construct and institutional approaches to it may be viewed through multiple lenses including, inter alia, international partnerships, study abroad, faculty and student exchange programs, and international branch campuses (Altbach \& Knight, 2007; Knight, 2008). Even so, studies suggest that institutions of higher education in Africa overwhelmingly service their internationalization goals, mainly capacity building for faculty and knowledge production, through international partnerships (Egron-Polak \& Hudson, 2014; Ishengoma, 2016; Knight, 2008; Kot, 2016). By way of definition, international partnerships may be construed as collaborations between institutions of higher and postsecondary education with the purpose of addressing mutual priorities (Ishengoma, 2016; Knight, 2008; Kot, 2016; Wanni, Hinz, \& Day, 2010). It is worth pointing out here that international development agencies are important actors in the politics of 
education for development. These organizations participate in international education in a variety of ways, perhaps none more important than funding and facilitating collaboration activities and initiatives (Heyneman \& Lee, 2016). Nonetheless, considering the proliferation of international partnerships in Africa's higher education landscape (British Council, 2017; Egron-Polak \& Hudson, 2014; Ishengoma, 2016; Knight, 2008; Kot, 2016), it is not surprising that outgoing mobility for faculty emerges as the top-ranked internationalization activity for universities there (Egron-Polak \& Hudson, 2014). In Nigeria, for instance, a study by the British Council (2017) reports that out of 143 accredited universities, $45(31.9 \%)$ have transnational education partnerships, even though less than $30 \%$ of the existing partnerships are active. Interestingly, the study attributes the low participation rates among faculty in activities set forth in collaboration agreements to low levels of awareness. Traditionally, international partnerships and collaborations have been between institutions in the global North and those in the global South in service of development needs (Ishengoma, 2016; Knight, 2008; Kot, 2016). Given Africa's colonial legacy and its veritable influence on the development of higher education systems (Weeks, 2008; Teferra \& Altbach, 2004), one presumes that most linkages largely track historical ties. Still, recent trends point to growing South-South collaborations (Ishengoma, 2016, Kot, 2016).

In light of the foregoing discussion, I argue that international partnerships provide a useful framework for examining patterns of faculty engagement in internationalization in the context of higher education in Africa. Specifically, they provide an enabling and structured environment wherein a broad range of internationalization initiatives occur (Egron-Polak \& Hudson, 2014; Kot, 2016). It can be postulated that international engagement benefits individual faculty in terms of career development, particularly professional learning leading to enhanced academic profile and increased competitiveness in the job market (Kot, 2016). Existing research, though limited in scope, has indicated that international engagement involves a substantial commitment of time and resources on the part of the faculty (Beatty, 2013; Dewey \& Duff, 2009; Nyangau, 2018). This implies that absent the broader institutional context for internationalization, faculty would be less likely to seek out and embed international dimensions into their courses. Individual agency is of course an important aspect to consider in regard to motivations of faculty scholarly and creative endeavors (Ford, 1992, Blackburn \& Lawrence, 1995). Agency, Sen (1985) explains, refers to "what the person is free to do and achieve in pursuit of whatever goals or values he or she regards as important" (p. 203). Still, while faculty may feel efficacious about international activities, the lived fiscal realities of the academic profession in Africa, especially the scarcity of resources, low salaries, and a growing reliance on part-time appointments (Altbach, Reisberg, \& Rumbley, 2009; Jowi, 2009; Teferra \& Altbach, 2004), severely constrain their flexibility.

All told, internationalization serves a variety of practical purposes for universities in Africa, especially as it relates to enhancing educational quality, international reputation and academic rankings in the ever-influential global institutional rankings systems (Egron-Polak \& Hudson, 2014; Ishengoma, 2016; Knight, 2008). Yet virtually no studies have focused attention on rationales that underlie faculty international activities in that context. Given the paucity of empirical research on this topic, studies that illuminate the individual drivers for faculty internationalization-related activities are warranted.

\section{Future Research}

First, this inquiry used a small sample of respondents drawn from disciplines in education, human services, and health professions and, as a result, further studies are needed to confirm the outcomes of this research. Moreover, studies should examine drivers of faculty 
involvement in internationalization across a wider variety of disciplines to determine whether motivations vary based on academic field. Investigating this issue is especially worthwhile because although it is conceivable that involvement in outreach activities including internationalization has a more "natural" fit for faculty in education and related disciplines, this may not be the case with other disciplines. For instance, whereas a faculty member in curriculum and instruction or international affairs might be motivated to improve and enrich the educational experience for students, a physicist, a chemist, or an engineer might be much more interested in international contacts and/or international collaboration to benefit his or her research agenda.

Second, this inquiry was conducted at a large public research university in the Midwest. Future research should examine whether rationales of faculty international engagement differ across institutional types. Moreover, as academic reward structures differ, research should examine whether rationales of faculty international activities vary across institutional types. Additionally, studies should investigate whether influences that underlie international engagement vary between tenure-track and non-tenure track faculty, as well as at institutions without tenure. Lastly, there are vast differences in systems of higher education around the world, especially in relation to faculty reward structures. Accordingly, studies should examine whether variability exists in rationales that underlie faculty activities in different systems and different cultures.

\section{References}

Abes, E. S., Jackson, G., \& Jones, S. R. (2002). Factors that motivate and deter faculty use of service-learning. Michigan Journal of Community Service Learning, 9, 5-17.

Ackers, L. (2005). Moving people and knowledge: Scientific mobility in the European Union. International Migration, 43, 99-131.

Altbach, P. (2016). Global perspectives on higher education. Baltimore, MD: Johns Hopkins University Press.

Altbach, P. G. (1998). Comparative perspectives on higher education for the twenty-first century. Higher Education Policy, 11(4), 347-356.

Altbach, P. G., Reisberg, L., \& Rumbley, L. E. (2009). Trends in global higher education: Tracking an academic revolution. Report prepared for UNESCO 2009 World Conference on Higher Education. Paris: UNESCO

Altbach, P., \& Knight, J. (2007). Internationalization of higher education: Motivations and realities. Journal of Studies in International Education, 11, 290-305.

American Council on Education (ACE). (2012). Mapping internationalization on US campuses. Washington, DC: Center for Internationalization and Global Engagement.

Austin, A. E., \& Gamson, Z. F. (1983). Academic workplace: New demands, heightened tensions. Washington, DC: Association for the Study of Higher Education.

Bandura, A. (1997). Self-efficacy: The exercise of self-control. New York, NY: Freeman

Bandura, A. (1977). Self-efficacy: Toward a unifying theory of behavioral change. Psychological Review, 84, 191-215.

Beatty, M. R. (2013). Factors influencing faculty participation in internationalization at the University of Minnesota's schools of nursing and public health: A case study. (Unpublished doctoral dissertation). University of Minnesota, Minneapolis.

Blackburn, R. T., \& Lawrence, J. H. (1995). Faculty at work: Motivation, expectation, satisfaction. Baltimore, MD: Johns Hopkins University Press. 
Boyer, E. L. (1990). Scholarship reconsidered: Priorities of the professoriate. Washington, DC: The Carnegie Foundation for the Advancement of Teaching.

Boyer, E. L. 1996. The scholarship of engagement. Journal of Public Service and Outreach, 1, $11-20$.

Bray, M. (2016). Actors and purposes in comparative education. In M. Bray, B. Adamson \& M. Mason (Eds.), Comparative Education Research: Approaches and Methods (pp. 19 - 48). Hong Kong: Comparative Education Research Centre.

British Council (2017). The transnational education landscape in Nigeria's higher education system. Retrieved from

https://www.britishcouncil.org/sites/default/files/british_council_full_report_14_ 8_18.pdf

Carini, R. M., Kuh, G. D., \& Klein, S. P. (2006). Student engagement and student learning: Testing the linkages. Research in Higher Education, 47, 1-32.

Carlson, J. S., \& Widaman, K. F. (1988). The effect of study abroad during college on attitudes toward other cultures. International Journal of Intercultural Relations, 12, 1-17.

Charmaz, K. (2006). Constructing grounded theory: A practical guide through qualitative analysis. Thousand Oak, CA: Sage.

Charmaz, K. (2014). Constructing grounded theory (2nd ed.). Thousand Oaks, CA: Sage.

Childress, L. K. (2009). Internationalization plans for higher education institutions. Journal of Studies in International Education, 13, 289-309.

Childress, L. K. (2010). The twenty-first century university: Developing faculty engagement in internationalization. New York, NY: Peter Lang.

Clarke, I., Flaherty, T. B., Wright, N. D., \& McMillen, R. M. (2009). Student intercultural proficiency from study abroad programs. Journal of Marketing Education, 31, 173-181.

Darby, A., \& Newman, G. (2014). Exploring faculty members' motivation and persistence in academic service-learning pedagogy. Journal of Higher Education Outreach and Engagement, 18, 91-120.

Denzin, N., \& Lincoln, Y. (Eds.). (2000). Handbook of qualitative research (2nd ed.). Thousand Oaks, CA: Sage.

de Wit, H. (2000). Changing rationales for the internationalization of higher education. Internationalization of higher education: An institutional perspective. Bucharest, Romania: UNESCO/CEPES.

de Wit, H. (2002). Internationalization of higher education in the United States of America and Europe: A historical, comparative, and conceptual analysis. Westport, CT: Greenwood Press.

de Wit, H. (Ed.). (1995). Strategies of internationalization of higher education. A comparative study of Australia, Canada, Europe and the United States. Amsterdam, Netherlands: European Association for International Education.

Dewey, P., \& Duff, S. (2009). Reason before passion: Faculty views on internationalization in higher education. Higher Education, 58, 491 - 504.

Egron-Polak, E. (2012). Internationalization of higher education: A few global trends and regional perspectives. In C. T. Ennew, \& D. Greenaway (Eds.), The Globalization of Higher Education (pp. 1-16). New York.

Egron-Polak, A. \& Hudson, R. (2014). Internationalization of higher education: Growing expectations, fundamental values. Paris: International Association of Universities.

Erez, M. \& Earley, P., C. (1993). Culture, self-identity, and work. New York, NY: Oxford University Press. 
Ford, M. E. (1992). Motivating humans: Goals, emotions, and personal agency beliefs. Newbury Park, CA: Sage.

Eyler, J., \& Giles, D. E., Jr. (1999). Where's the learning in service-learning? San Francisco, CA: Jossey-Bass.

Finkelstein, M. J., Walker, E., \& Chen, R. (2013). The American faculty in an age of globalization: Predictors of internationalization of research content and professional networks. Higher Education, 66, 325-340.

Finkelstein, M., \& Sethi, W. (2014). Patterns of faculty internationalization: A predictive model. In F. Huang, M. Finkelstein, \& M. Rostan (Eds.). The internationalization of the academy; Changes, realities and prospects (pp. 237-257). New York, NY: Springer.

Finkelstein, M., Walker, E., \& Chen, R. (2009). The internationalization of the American faculty: Where are we, what drives or deters us? Hiroshima, Japan: The Research Institute for Higher Education (RIHE).

Friesen, R. (2013). Faculty member engagement in Canadian university internationalization: A consideration of understanding, motivations and rationales. Journal of Studies in International Education, 17, 209-227.

Glaser, B. G., \& Srauss, A. L. (1967). The discovery of grounded theory. New York, NY: de Gruyter.

Gordon, E. W., Miller, F., \& Rollock, D. (1990). Copying with communicentric bias in knowledge production in the social sciences. Educational Researcher, 19, 14-19.

Green, M. F. (2003). The challenge of internationalizing undergraduate education: Global learning for all. Paper presented at the Global Challenges and US Higher Education Conference, Duke University, NC.

Green, M. F., \& Olson, C. (2003). Internationalizing the campus: A user's guide. Washington, DC: American Council on Education.

Hammond, C. (1994). Integrating service and academic study: Faculty motivation and satisfaction in Michigan higher education. Michigan Journal of Community Service Learning, 1, 21-28.

Heyneman, S. \& Lee, B. (2016). International organizations and the future of education assistance. International Journal of Educational Development, 48, 9-22

Hudzik, J. K. (2011). Comprehensive internationalization: From concept to action. Washington, DC: NAFSA: Association of International Educators.

Ishengoma, J. (2016). Strengthening higher education space in Africa through North-South partnerships and links: Myths and realities from Tanzania public universities. Comparative and International Education 45(1), 1-17.

Jones, E. (2014). Graduate employability and internationalization of the curriculum at home. International Higher Education, 6, 6-8.

Jowi, J. (2009). Internationalization of Higher Education in Africa: Developments, Emerging Trends, Issues and Policy Implications. Higher Education Policy, 22(2) 263-281.

Kehm, B. \& Teichler, U. (2007). Research on internationalization in higher education. Journal of studies in international education, 11(3/4), 231-239.

Kot, F. C. (2016). The perceived benefits of international partnerships in Africa: A case of two public universities in Tanzania and the Democratic Republic of Congo. Higher Education Policy, 29(1), 41-62.

Knight, J. (1994). Internationalization: Elements and checkpoints (Research Monograph, No. 7). Ottawa, Canada: Canadian Bureau for International Education.

Knight, J. (1999). A time of turbulence and transformation for internationalization. Ottawa, Ontario, Canada: Canadian Bureau for International Education. 
Knight, J. (2004). Internationalization Remodeled: Definition, Approaches, and Rationales. Journal of Studies in International Education, 8(1), 5-31.

Knight, J. (2006). Internationalization: Concepts, complexities and challenges. In J. Forest \& P. Altbach (Eds.), International handbook of higher education (pp. 207-228). New York, NY: Springer.

Knight, J. (2008). The internationalization of higher education: Complexities and realities. In D. Teferra \& J. Knight (Eds.), Higher education in Africa: The international dimension (pp. 1-43). Boston, MA: AAU/CIHE.

Knight, J., \& de Wit, H. (Eds.). (1997). Internationalization of higher education in Asia Pacific countries. Amsterdam, Netherlands: European Association for International Education.

Knight, J. (2003). Updated internationalization definition. International Higher Education, 33, 2-3.

Knight, J., \& de Wit, H. (Eds.). (1997). Internationalization of higher education in Asia Pacific countries. Amsterdam, Netherlands: European Association for International Education.

Knight, P., \& Yorke, M. (2004). Learning, curriculum and employability in higher education. New York, NY: RoutledgeFalmer.

Kuh, G. D., Kinzie, J., Buckley, J. A., Bridges, B. K., \& Hayek, J. C. (2006). What matters to student success: A review of the literature commissioned report for the national symposium on postsecondary student success: Spearheading a dialog on student success. Washington, DC: National Postsecondary Education Cooperative.

Merriam, S. B. (2009). Qualitative research: A guide to design and implementation. San Francisco, CA: Jossey-Bass.

Morais, D. B., \& Ogden, A. C. (2011). Initial development and validation of the global citizenship scale. Journal of Studies in International Education, 15, 445-466.

National Survey of Student Engagement. (2007). Experiences that matter: Enhancing student learning and success. Center for Postsecondary Research. Bloomington, IN: Indiana University.

Neumann, A. (2009). Professing to learn: Creating tenured lives and careers in the American Research University. Baltimore, MD: The John Hopkins Press.

Niehaus, E., \& Williams, L. (2016). Faculty transformation in curriculum transformation: The role of faculty in campus internationalization. Innovative Higher Education, 41, 59-74.

Nyangau, J. Z. (2018). A qualitative study of faculty motivations of engagement in internationalization. (Unpublished doctoral dissertation). Kent State University, Kent.

O’Meara, K. (2002). Uncovering the values in faculty evaluation of service as scholarship. The Review of Higher Education, 26, 57-80.

O’Meara, K. (2005). Encouraging multiple forms of scholarship in faculty reward systems. Does it make a difference? Research in Higher Education, 46, 479-510.

O'Meara, K. (2008). Motivation for faculty community engagement: Learning from exemplars. Journal of Higher Education Outreach and Engagement, 12, 7-29.

O’Meara, K., Sandmann, L. R., Saltmarsh, J., \& Giles, D. E. (2011). Studying the professional lives and work of faculty involved in community engagement. Innovative Higher Education, 36, 83-96.

O’Meara, K., Terosky, A. L., \& Neumann, A. (2008). Faculty careers and work lives: A professional growth perspective. San Francisco, CA: Jossey-Bass. 
Pollack, S. (1999). Early connections between service and education. In T. K. Stanton, D. E. Giles Jr., \& N. I. Cruz (Eds.), Service-learning: A movement's pioneers reflect on its origins, practice, and future (pp. 12-32). San Francisco, CA: Jossey-Bass.

Rice, E., Sorcinelli, M. D., \& Austin, A. E. (2000). Heeding new voices: Academic careers for a new generation. New Pathways: Faculty Careers and Employment for the 21st Century. Washington, DC: American Association of Higher Education.

Sen, A. (1985). Well-being, agency and freedom: The Dewey lectures. The Journal of Philosophy, 82, 169-221.

Siaya, L., \& Hayward, F. M. (2003). Mapping internationalization on U.S. campuses. Washington, DC: American Council on Education.

Schattle, H. (2009). Global citizenship in theory and practice. In R. Lewin (Ed.), The handbook of practice and research in study abroad: Higher education and the quest for global citizenship (pp. 3-20). New York, NY: Routledge.

Spaulding, S., \& Flack, M. (1976). The world's students in the United States: A review and evaluation of research on foreign students. New York, NY: Praeger.

Stromquist, N. P. (2007). Internationalization as a response to globalization: Radical shifts in university environments. Higher Education, 53, 81-105.

Teferra, D. \& Altbach, P. G. (2004). African higher education: challenges for the 21 st century. Higher Education, 47(1), 21-50.

Wanni, N., Hinz, S. \& Day, R. (2010). Good practices in educational partnerships guide: UK-Africa higher education $\Xi^{\circ}$ further education partnerships. London: Association of Commonwealth Universities.

Weeks, S. H. (2008). National approaches to internationalization: Historical perspectives and socioeconomic influences. In D. Teferra \& J. Knight (Eds.), Higher education in Africa: The international dimension (pp. 1-43). Boston, MA: AAU/CIHE.

Vaira, M. (2004). Globalization and higher education organizational change: A framework for analysis. Higher Education, 48, 483-510.

Van der Wende, M. (1997). Missing links: The relationship between national policies for internationalization and those for higher education in general. In T. Kalvermark \& M. Van der Wende (Eds.), National policies for the internationalization of higher education in Europe (pp. 10-3 1). Stockholm, Sweden: National Agency for Higher Education.

\section{About the Author}

Josiah Z. Nyangau, PhD, currently serves as assistant director of assessment in the Office of Institutional Effectiveness at Louisiana State University. He previously served as program coordinator for Accreditation, Assessment and Learning at Kent State University, where he also taught in the Higher Education Administration program. He earned his bachelor's degree in Education from Kenyatta University, master's degree in Geography from Ohio University, and PhD in Higher Education Administration from Kent State University. His research interests address issues related to the influences of globalization on higher and postsecondary education, especially the internationalization of higher education, curriculum in higher education, education policy learning and borrowing, international partnerships, and accreditation or quality assurance for higher education. His research also explores assessment for learning in higher education as well as academic reward systems and faculty work lives. 